\title{
BANCO DE OSSOS
}

BONE BANK

Paulo Gilberto Cimbalista de Alencar ${ }^{1}$, Inácio Facó Ventura Vieira ${ }^{2}$

\section{RESUMO}

Bancos de ossos são necessários para prover material biológico para uma série de procedimentos ortopédicos. A crescente necessidade de tecidos musculoesqueléticos para transplante é decorrente do desenvolvimento de novas técnicas cirúrgicas e fez com que diversos serviços se dispusessem a ter sua própria fonte de tecidos para transplante. Para aumentar a segurança dos tecidos transplantados, normas foram impostas pelo governo para o funcionamento dos bancos, o que limitou o número de instituições autorizadas. O bom desempenho de um banco de ossos depende de um rígido controle de todas as etapas, passando pela formação de equipes bem treinadas para captação, pela seleção de doadores, pela realização de diversos exames nos tecidos captados e pelo controle rigoroso das técnicas de processamento utilizadas. A associação desses fatores faz com que a abrangência do uso e do número de pacientes receptores seja ampliada, a contaminação de tecidos seja de incidência estatisticamente desprezível e haja rastreabilidade entre doadores e receptores. Este trabalho descreve as considerações técnicas quanto ao funcionamento de um banco, uso de enxertos e aplicações ortopédicas, bem como aspectos éticos e principais obstáculos enfrentados.

Descritores - Bancos de Ossos; Enxerto Homólogo; Transplante Ósseo; Cirurgia Ortopédica

\section{ABSTRACT}

Bone banks are necessary to provide biological material for a series of orthopedic procedures. The growing need for musculoskeletal tissues for transplantation is due to the development of new surgical techniques, and has made it so that a variety of services were willing to have their own source of tissue for transplantation. To increase the safety of transplanted tissues, standards for the operation of banks were imposed by the government, which limited the number of authorized institutions. The good performance of a bone bank depends on strict control of all stages, from the formation of well-trained teams for capturing, for donor selection, for conducting various tests on the tissues obtained, and by the strict control of the processing techniques used. The combination of these factors makes it so that the scope of use and the number of recipient patients increases, the incidence of tissue contamination is statistically insignificant, and that there is traceability between donors and receptors. This paper describes the technical considerations regarding the functioning of a bank, use of grafts and orthopedic applications, as well as ethical aspects and the main obstacles encountered.

Keywords - Bone Banks; Allograft; Bone Transplantation; Orthopedic Surgery

\section{INTRODUÇÃO}

A necessidade de reposição de tecido musculoesquelético devido a perdas causadas por diversas situações é um problema cada vez mais comum na prática cirúrgica. Com a maior longevidade da população ao lado do fato que indicações cirúrgicas são cada vez mais frequentes em pacientes jovens, a busca por uma solução duradoura implica a utilização de métodos de reconstrução biológicos.
Não há, até o momento, melhor material para substituição de perdas ósseas que o próprio tecido humano e o melhor, do ponto de vista biológico, é o tecido autólogo, isto é, do próprio paciente. Contudo, as complicações no sítio doador (aumento do tempo de cirurgia, dor, sangramento, fraturas, lesões neurovasculares) e a necessidade de formatos específicos e de grandes quantidades de material biológico faz com que o uso de banco de tecidos seja mais adequado na maioria das situações ${ }^{(1,2)}$.

1 - Chefe do Grupo de Cirurgia de Quadril e Joelho do Hospital de Clínicas da Universidade Federal do Paraná.

2 - Médico Ortopedista do Grupo de Cirurgia de Quadril e Joelho do Hospital de Clínicas - UFPR.

Correspondência: Av. Nossa Senhora Aparecida, 286, Bairro Seminário - Curitiba - PR. 80440-000 - E-mail: pa@clinicapauloalencar.com, inacioventura@hotmail.com

Trabalho recebido para publicação: 05/10/10, aceito para publicação: 05/10/10. 
Historicamente, os bancos de ossos existem desde a década de 50 no Brasil, ocorrendo, em meados dos anos 90, a regulamentação das práticas a serem seguidas pelos bancos de tecidos - fato que impôs uma série de restrições, limitando o número de bancos e cirurgiões autorizados a utilizar tecido musculoesquelético.

\section{BIOLOGIA DO ENXERTO ÓSSEO}

A consolidação do enxerto ao tecido ósseo hospedeiro se dá mediada por três fenômenos biológicos: osteogênese, osteoindução e osteocondução ${ }^{(3)}$. Entende-se por osteogênese a capacidade de células vivas (osteoblastos) manterem a produção de substância osteoide, fato que ocorre eventualmente apenas com enxertos autólogos. Osteoindução é a diferenciação de células pluripotenciais do hospedeiro em osteoblastos, através de uma série de mecanismos, em que as diversas famílias de fatores de crescimento exercem papel importante. Por último, osteocondução é o processo em que os canalículos do osso transplantado agem como um guia para o crescimento de pontes de osteoblastos do tecido ósseo novo, proveniente do hospedeiro. Grande número de enxertos homólogos e substitutos ósseos são exclusivamente osteocondutivos ${ }^{(4)}$.

\section{CONSIDERAÇÕES TÉCNICAS}

\section{Seleção de doadores}

É feita criteriosamente pelo coordenador da equipe de captação e pelo diretor médico do banco, levando em consideração dados como idade e sexo do doador, causa da morte, história médica pregressa, exame físico e numerosos testes laboratoriais.

A maior complicação a ser evitada é a transmissão de doenças do doador ao receptor, seja de natureza viral (HIV, hepatite) ou bacteriana, causada por um organismo presente no doador ou por contaminação no momento da captação dos tecidos esqueléticos ${ }^{(5)}$. Para evitar esta complicação, podem ser utilizados métodos de esterilização (autoclavagem, óxido de etileno, irradiação), cada um com suas vantagens e desvantagens, ou processos estéreis desde a captação até o armazenamento final, com coletas seriadas de exames alternadas com períodos de quarentena. O protocolo a ser cumprido antes da liberação faz com que haja descarte de tecidos após a captação em até 30\% das vezes, devido ao seu rigor absoluto. Em nosso banco, após mais de
20.000 tecidos terem sido utilizados em cirurgias, não há um caso comprovado de transmissão de doenças ao doador $^{(6-8)}$ (Figura 1).

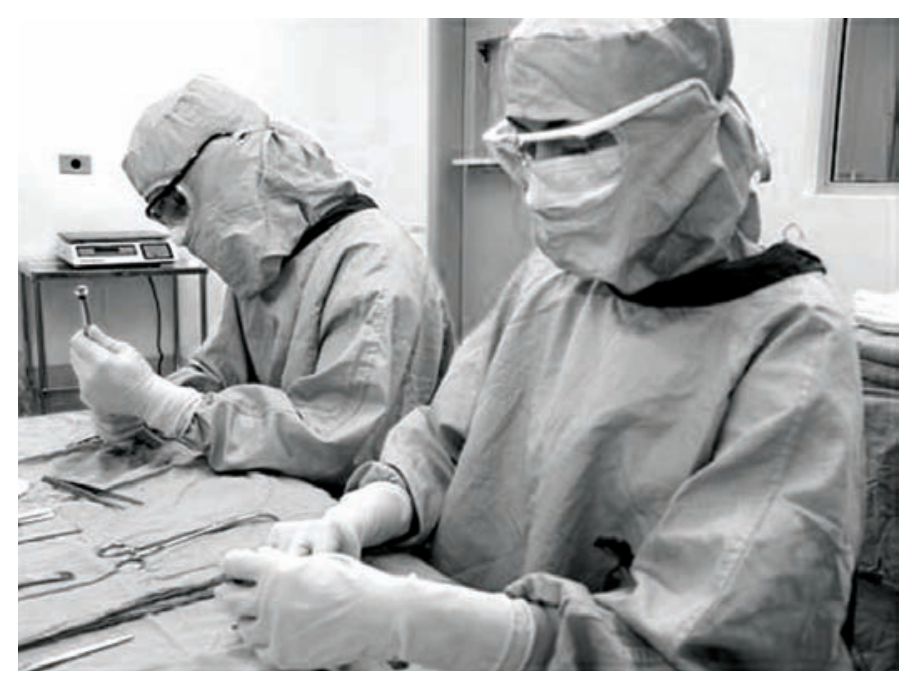

Figura 1 - Equipe paramentada realizando processamento de tecidos de forma estéril.

\section{Captação de tecidos}

As equipes de coleta devem ser regularmente registradas nas centrais de transplantes para terem amparo legal e serem notificadas sobre doadores, não apenas em seus hospitais, mas também em outras instituições, muitas vezes fora de sua cidade ou estado. Há dois tipos de doadores de tecidos homólogos: vivos, representados principalmente pelas doações de cabeças femorais após artroplastias totais de quadril, que têm a vantagem de ser possível a reconvocação dos pacientes doadores para novos testes em casos suspeitos; e doadores cadáveres, dos quais pode ser coletada quantidade muito maior de tecidos e praticamente de qualquer segmento do esqueleto, além de serem em geral doadores jovens, cuja qualidade do tecido ósseo é melhor que a dos doadores vivos.

\section{Coleta de tecidos}

Deve ser realizada de forma muito cautelosa, geralmente por uma equipe formada por quatro membros (dois cirurgiões, um embalador e um auxiliar), seguindo todas as orientações de antissepsia e assepsia de uma cirurgia ortopédica de grande porte (Figura 2). Após a retirada, são coletados materiais para exames. As peças são embaladas individualmente, identificadas e transportadas em caixas térmicas com gelo seco ou comum. Uma exigência legal e um ponto de respeito às famílias dos doadores é a reconstrução da estrutura corporal do cadáver, o que é feito com peças de PVC previamente montadas (Figura 3). 


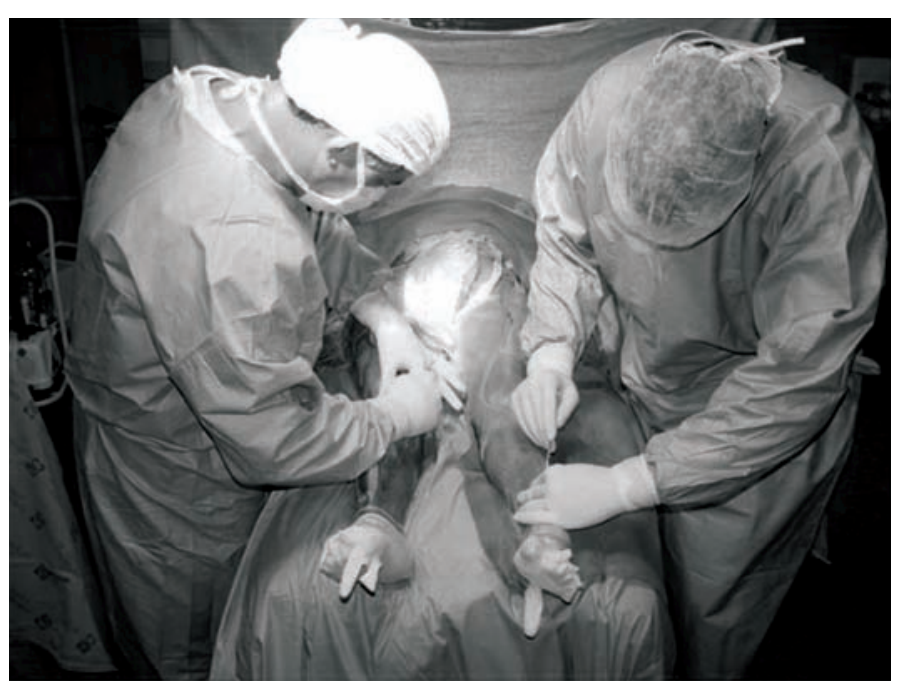

Figura 2 - Captação seguindo princípios de assepsia como em cirurgia ortopédica de grande porte.

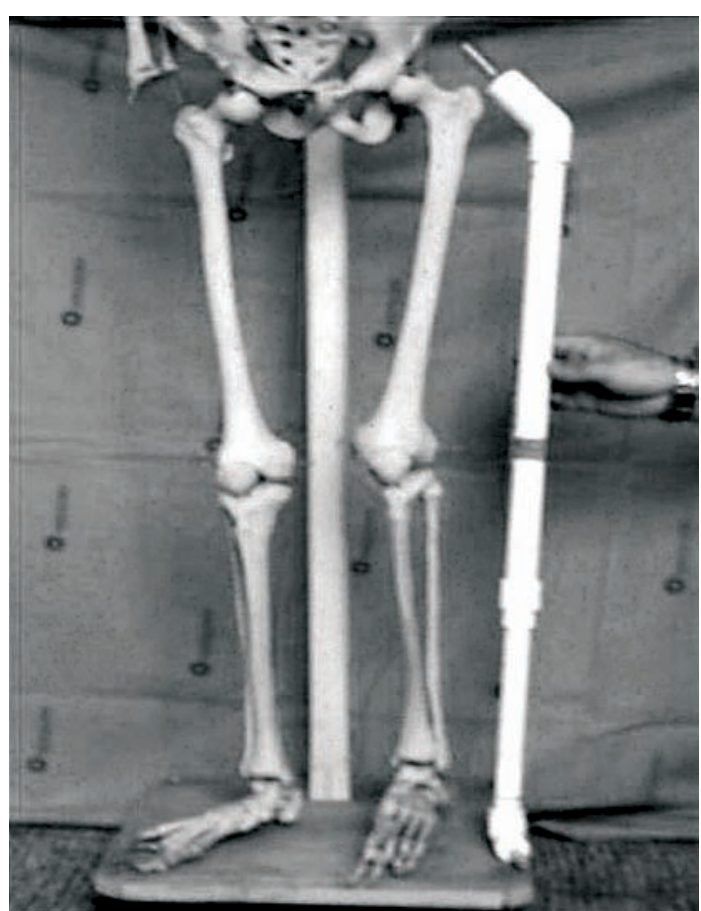

Figura 3 - Prótese de PVC para reconstrução do cadáver.

\section{Estocagem}

Os tecidos são geralmente mantidos em freezers em temperatura de 85 graus Celsius abaixo de zero. Estes aparelhos possuem gráficos com controle de temperatura e estão ligados ao gerador do hospital para eventuais quedas de energia. Possuem também alarme e suprimento de CO2 líquido para segurança adicional. Em condições ideais e em temperatura constante, os tecidos podem ficar estocados por um período de cinco anos, de acordo com as normas da Anvisa (Agência Nacional de Vigilância Sanitária) e da AATB (American Association of Tissue Banks).

\section{CONSIDERAÇÕES ÉTICAS E LEGAIS}

No Brasil, o Ministério da Saúde reconheceu formalmente através de portaria, em agosto de 2000, a existência dos bancos de tecidos musculoesqueléticos, iniciando-se a partir daí a regulamentação do funcionamento dos mesmos. Alguns aspectos próprios foram definidos, como a necessidade de um responsável técnico com experiência, a seleção adequada de doadores e requisitos mínimos de estocagem e processamento.

O consentimento do doador vivo, ou de parentes próximos, em caso de cadáveres, é obrigatório para captação de tecidos. A autorização da captação implica o fornecimento de dados da história médica pregressa e hábitos de vida, que são fundamentais na seleção de doadores.

Apenas os exames complementares dos tecidos não são suficientes para sua liberação em uso cirúrgico, mas deve-se proceder a um somatório de diversos itens. Transplante de tecidos, seja qual o método usado na seleção e processamento, não é isento do risco de transmissão de doenças, e o paciente deve ser notificado por seu médico e assinar um termo de consentimento informado.

Com regras definidas do funcionamento de bancos de ossos, mudou-se a prática cirúrgica em nosso país. Havia riscos substanciais no uso de freezers convencionais, na maior parte das vezes sem a supervisão adequada de um responsável médico e sujeitos a problemas na identificação de doadores, falhas de energia e falta de controle técnico adequado do equipamento. Após o surgimento da AIDS, a necessidade de maior controle levou à implantação de bancos estruturados com equipes de trabalho permanentes e técnicos treinados nas diversas fases de captação, seleção, estocagem, processamento e distribuição dos tecidos musculoesqueléticos.

Uma questão que desperta polêmica é se cabe pagamento pelo uso de tecidos humanos. Como outras instituições ligadas a transplantes, bancos de tecidos musculoesqueléticos têm obrigatoriamente caráter não lucrativo, e apenas os custos referentes às diversas fases do processo são repassados. Com a evolução cultural, aumento do número de doações e a maior utilização de tecidos musculoesqueléticos em cirurgias, pode se chegar a uma situação de equilíbrio, inclusive com cobertura de custos por fontes pagadoras públicas e privadas, para estender os benefícios do banco a um maior número de pessoas possíveis ${ }^{(9)}$. 


\section{APLICAÇÕES EM ORTOPEDIA}

De uma maneira geral, o emprego de tecidos provenientes de bancos de tecidos musculoesqueléticos em ortopedia aumentou significativamente nos últimos anos por várias razões: 1) impossibilidade de obtenção de grandes quantidades de osso autólogo; 2) morbidade do local de retirada do enxerto; 3) aumento no número de revisões de artroplastias de quadril e joelho; e 4) desenvolvimento de novas técnicas cirúrgicas que dependem de osso homólogo ${ }^{(10)}$.

A utilização destes tecidos é ampla nas diversas especialidades da ortopedia. Na traumatologia, por exemplo, com o aumento progressivo dos casos de lesões de alta energia, os índices crescentes de perdas ósseas segmentares e de pseudartroses têm feito com que o uso de osso homólogo seja mais frequente.

O aumento da expectativa de vida e a indicação de artroplastias em pacientes cada vez mais jovens fez com que o número de cirurgias para colocação de próteses de quadril e joelho e consequentemente o número de revisões aumentasse muito nas últimas décadas. Nestas cirurgias frequentemente os pacientes apresentam perda óssea de diversas etiologias (infecção, osteólise, soltura asséptica etc), e a reposição do estoque ósseo pode dar tanto um melhor resultado a curto e longo prazos como facilitar uma possível revisão subsequente, caso seja necessária ${ }^{(9,11-14)}$ (Figuras 4A, 4B e 4C).

Nos casos de ressecção de segmentos ósseos devido a tumores malignos, uma das opções é a utilização de enxertos homólogos maciços para a reconstrução dos $\operatorname{membros}^{(15)}$. As artrodeses, entre elas as da coluna, são cirurgias nas quais frequentemente o volume de enxerto necessário para o procedimento nos leva a utilizar osso homólogo ${ }^{(1,2,16)}$.

Na ortopedia pediátrica o uso de tecidos de banco é particularmente interessante, pois a opção de enxerto autólogo é reduzida, principalmente em idades baixas. Operações em que frequentemente são utilizados tecidos ósseos são correções de escoliose, artrodeses do pé, pseudartroses congênitas, entre outras.

Em medicina esportiva, o tratamento de pacientes jovens e ativos favoreceu o uso de material biológico em técnicas como transplante de meniscos. Há um uso crescente de tecidos transplantados, com um leque cada vez maior de aplicações. O uso de enxertos tendinosos em reconstrução do ligamento cruzado anterior do joelho é consagrado na literatura médica e é a rotina em alguns serviços $^{(10,17-19)}$ (Figuras 5A, 5B e 5C).

Há uma gama de técnicas cirúrgicas descritas em áreas diversas da ortopedia, em todas as subespecialidades, além das já citadas, e diversas novas técnicas serão criadas e utilizadas na rotina da prática cirúrgica no futuro. As condições para tanto, que em verdade se sobrepõem, são o aumento do número de doadores de tecido e o treinamento de cirurgiões nas diversas técnicas de utilização de tecidos musculoesqueléticos.

\section{PERSPECTIVAS}

Apesar do grande potencial, o Brasil ainda tem uma taxa de utilização de enxertos ósseos muito inferior à dos países desenvolvidos; isto se dá, principalmente, devido a três fatores: o desconhecimento da população quanto
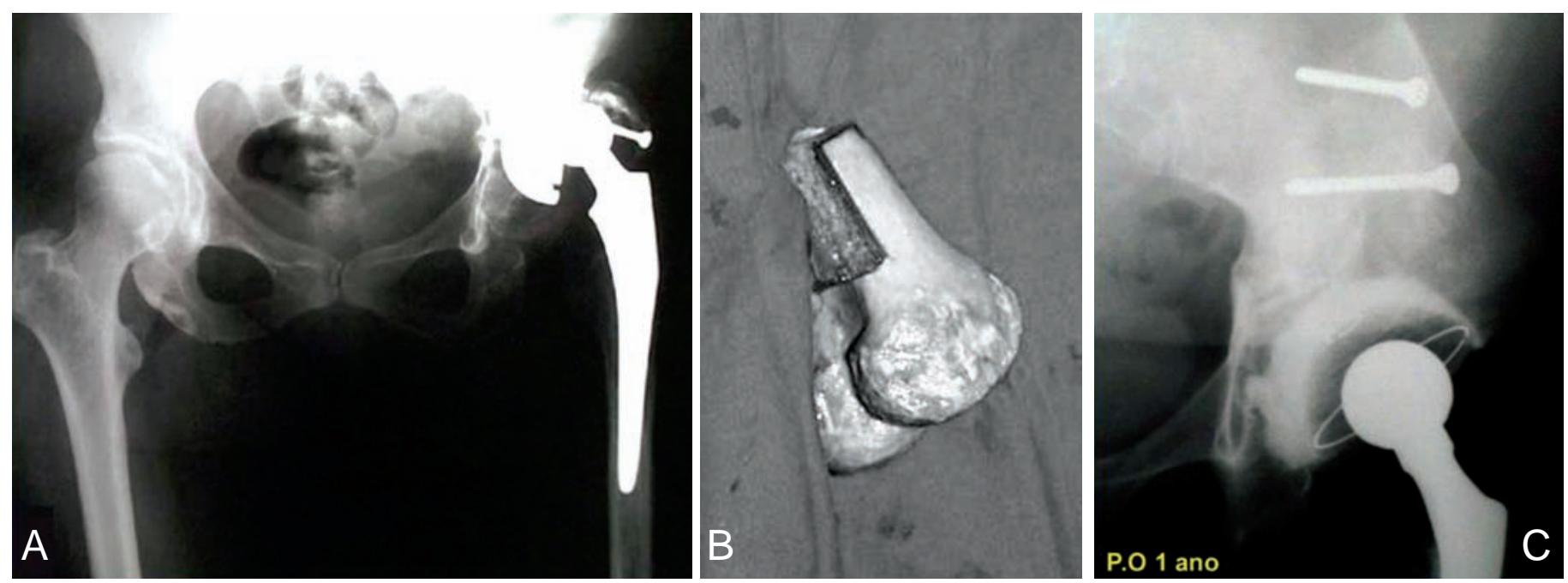

Figura 4 - Artroplastia de revisão de quadril. A) Soltura de componente acetabular com grande falha óssea. B) Enxerto homólogo de fêmur distal moldado em "7". C) Pós-operatório tardio de reconstrução acetabular com consolidação de enxerto evidente. 

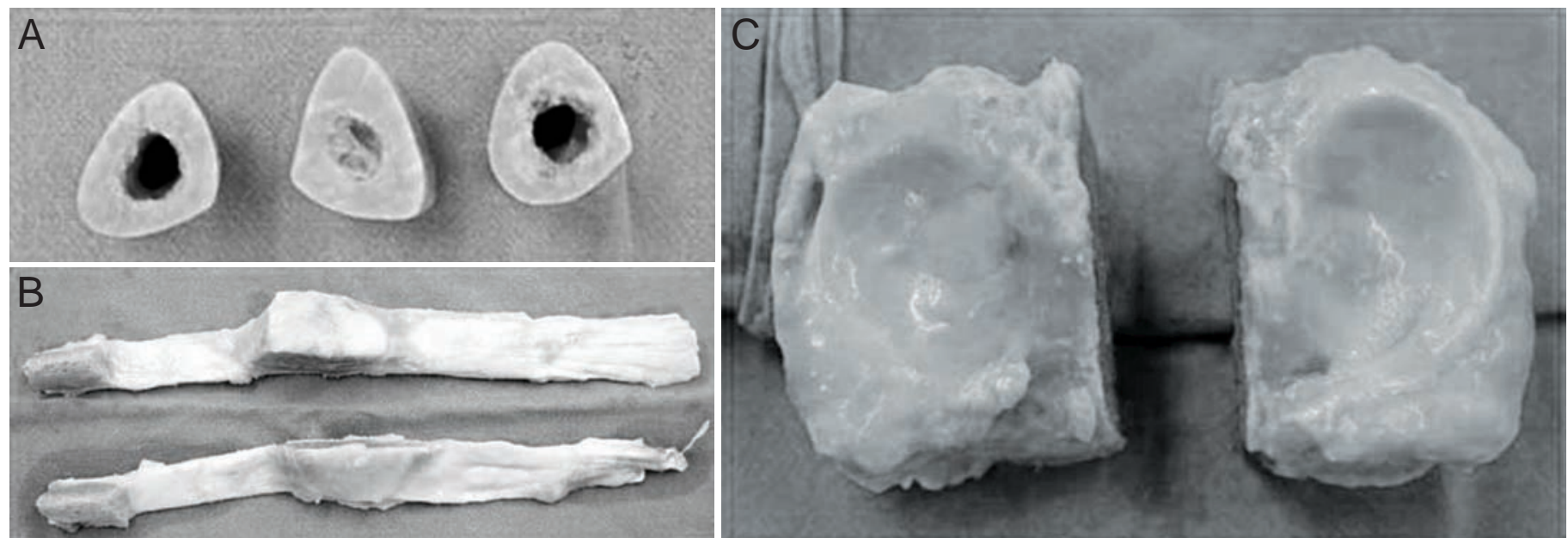

Figura 5 - Tipos de enxerto. A) "Anéis" corticais, que podem ser usados para preenchimento de cunhas em osteotomias. B) Tendões patelar e quadriciptal, para reconstruções multiligamentares. C) Enxerto osteocondral de tíbia proximal, para reconstruções pós-traumáticas ou tumorais.

à possibilidade de doação musculoesquelética, que tem sido suplantado por meio de várias campanhas e através de uma abordagem multidisciplinar junto aos familiares após o óbito; a falta de experiência de cirurgiões quanto às possibilidades de uso de enxertos homólogos e pouca familiaridade com as técnicas cirúrgicas, atenuada com a formação crescente de especialistas e um maior acesso aos bancos; e, primordialmente, aos empecilhos burocráticos impostos pelo Ministério da Saúde, dificultando a autorização de cirurgiões e estabelecimentos de saúde para o uso dos enxertos.

\section{REFERÊNCIAS}

1. Whang PG, Wang JC. Bone graft substitutes for spinal fusion. Spine J. 2003;3(2):155-65.

2. Vaccaro AR, Chiba K, Heller JG, Patel TCh, Thalgott JS, Truumees E, et al. Bone grafting alternatives in spinal surgery. Spine J. 2002;2(3):206-15.

3. Albrektsson T, Johanson C. Osteoinduction, osteoconduction and osseintegration. Eur Spine J. 2001;10(1):96-101.

4. Bauer TW, Muschler GF. Bone graft materials. An overview of the basic science. Clin Orthop Relat Res. 2000;(371):10-27.

5. Tomford WW. Transmission of disease through transplantation of musculoskeletal allografts. J Bone Joint Surg Am. 1995;77(11):1742-54.

6. Asada N, Tsuchiya H, Kitaoka K, Mori Y, Tomita K. Massive autoclaved allografts and autografts for limb salvage surgery. A 1-8 year follow-up of 23 patients. Acta Orthop Scand. 1997;68(4):392-5.

7. Thorén K, Aspenberg P. Ethylene oxide sterilization impairs allograft incorporation in a conduction chamber. Clin Orthop Relat Res. 1995;(318):259-64.

8. Forsell JH. Irradiation of musculoskeletal tissues In: Tomford WW. Musculoskeletal tissue banking. New York: Raven Press; 1993. p.149-80.

9. Villar RN. Tissue banking. In: Villar RN, Gross AE, McMinn D, editors. Revision hip arthroplasty. A practical approach to bone stock loss. Oxford: Butterworth Heineman; 1997. p. 26-32.

10. Alencar PG. Revisão em artroplastia total de quadril. Banco de ossos. Clínica
A verdadeira "lei seca” que alguns serviços de ortopedia sofrem provocou a busca de outras soluções cirúrgicas para a falta de tecidos humanos nas reconstruções, e com isso outros métodos se difundiram com uso de outros substitutos ósseos, em geral de custo mais elevado e eficiência duvidosa. Espera-se que mais equipes cirúrgicas, não só de ortopedia mas também de outras especialidades, mobilizem-se para vencer as barreiras do cadastramento junto ao Ministério de Saúde, ou que mudanças nas portarias pertinentes tornem o uso de tecidos musculoesqueléticos mais amplo no futuro breve.

Ortopédica. 2001;2(4):1173-88

11. Paprosky W, Laurence J, Cameron H. Femoral defect classification: clinical application. Orthop Rev. 1990;19(Suppl 9):9.

12. Slooff TJ, Schimmel JW, Buma P. Cemented fixation with bone grafts. Orthop Clin North Am. 1993 ;24(4):667-77.

13. Gie GA, Linder L, Ling RS, Simon JP, Slooff TJ, Timperley AJ. Impacted cancellous allografts and cement for revision total hip arthroplasty. J Bone Joint Surg Br. 1993;75(1):14-21.

14. Gross AE, Lavoie MV, McDermott P, Marks P. The use of allograft bone in revision of total hip arthroplasty. Clin Orthop Relat Res. 1985;(197):115-22.

15. Matejovsky Z Jr, Matejovsky Z, Kofranek I. Massive allografts in tumour surgery. Int Orthop. 2006;30(6):478-83.

16. Berven S, Tay BK, Kleinstueck FS, Bradford DS. Clinical applications of bone graft substitutes in spine surgery: consideration of mineralized and demineralized preparations and growth factor supplementation. Eur Spine J. 2001;10(Suppl 2):S169-77.

17. Mc Guire DA, Hendricks D. Allografts in sports medicine. Oper Tech Sports Med. 2007;15(1):46-52

18. Tom JA, Rodeo SA. Soft tissue allografts for knee reconstruction in sports medicine. Clin Orthop Relat Res. 2002;(402):135-56.

19. Willian DB. Fresh osteochondral allografting. Oper Tech Sports Med. 2000;8(2):158-62. 